\title{
$\alpha$-Chymotrypsin catalyses the synthesis of methotrexate oligomers
}

\author{
Jennifer Noro, Tarsila G. Castro, Artur Cavaco-Paulo*, Carla Silva* \\ Center of Biological Engineering, University of Minho, Campus de Gualtar, 4710-057, Braga, Portugal
}

\section{A R T I C L E I N F O}

\section{Keywords:}

$\alpha$-chymotrypsin

Methotrexate

Dimers

Oligomers

\begin{abstract}
A B S T R A C T
The enzymatic synthesis of methotrexate (MTX) catalysed by $\alpha$-chymotrypsin was studied for the first time. The proteolytic enzyme displayed activity for the synthesis of MTX oligomers composed by 6 repeating units $\left(\mathrm{DP}_{\mathrm{avg}}=1.5\right)$. For longer oligomers, molecular dynamics simulations confirmed that as the oligomeric chain grows its accommodation in the enzymes' active site is hindered, which is evidenced by a decrease of the binding energy associated. The full characterization of the oligomers produced was performed by nuclear magnetic resonance (NMR, ${ }^{1} \mathrm{H}$ and ${ }^{13} \mathrm{C}$ ), matrix-assisted laser desorption/ionization-time of flight (MALDI-TOF), electrospray ionization (ESI) and differential scanning calorimetry (DSC).
\end{abstract}

\section{Introduction}

The synthesis of polymeric drugs is an area with increasing interest for the pharmaceutical industry that aims to improve their pharmaceutical performance mainly in applications requiring a drug-controlled delivery. The controlled release, the improvement of safety and the biodistribution profile, are some of the benefits associated to the application of polymeric drugs [1]. The promising results obtained so far in clinical trials using polymer-anticancer drug conjugates have been raising the interest in the development of these type of drugs [2]. The conjugation of poly(ethylene glycol) (PEG) with drugs is one of the most studied strategies for the synthesis of polymer-drug conjugates, being that some of the developed products have already reached the market [3]. Recently, Suksiriworapong et al., synthetized a methotrexate-poly(glycerol adipate) conjugate, with improved toxicity for Saos- 2 cells than the unmodified methotrexate [4].

The polymer-drug conjugates or polymeric drugs are expected to be easily hydrolysed in vivo, depending on the type of bond established between the polymer and the drug or among the drug monomer units. Prodrugs containing amide bonds are highly stable in vivo, being hydrolysed by carboxylesterases [5], peptidases or proteases [6]. Proteases are enzymes commonly used for the hydrolysis of amide bonds between two amino acids. Despite their hydrolytic activity, they are also able to catalyse the inverse reaction, e.g. the formation of amide bonds (peptides) [7]. The chemoenzymatic peptide synthesis is considered as a green chemistry practice to replace the typical methods, liquid or solid phase peptide synthesis [8] taking advantage of the low costs associated with the use of proteases as catalyst [9]. Enzymes like papain, chymotrypsin, bromelain, trypsin and even lipase can be used as catalysts of these type of reactions [7]. Qin et al. [9] studied the use of papain for the biosynthesis of perfectly alternating oligopeptides. They started by the synthesis of the dipeptide AG-OEt, followed by the addition of papain and a short incubation period, isolating a peptide with a maximum of 21 AG units. The authors mentioned that an accurate choice of the ideal protease is crucial to afford oligomerization. This selection is essential to avoid hydrolysis and/or transamidation reactions during the process. The protease selection should rely on the specificity of the enzyme, determined by their specific hydrolytic properties between two amino acids. Following the same approach, the same authors [10] studied the ability of $\alpha$-chymotrypsin in the oligomerization between dipeptide KL-OEt. The selection of the protease relied on its high specificity for the hydrolysis between -LK- residues. After synthesis of the dipeptide KL-OEt, the $\alpha$-chymotrypsin was added, forming the expected oligomer. At a specific $\mathrm{pH}$ the enzyme triggered the formation of an hydrogel due to the spontaneous self-assembling of the KL chains into $\beta$-sheets. When papain was used for the same purpose, no hydrogel was formed, and a random sequence of oligopeptides was produced. The low selectivity of papain for the hydrolysis of -LK- bonds was responsible for the low reactional outcome.

Methotrexate is a commercially available drug for the treatment of several cancers, auto-immune diseases, and rheumatoid arthritis [11]. However, this drug presents several limitations, such as poor solubility in water, low resistance, high toxicity, and diverse side-effects associated to its administration [12]. Due to the presence of both amine and carboxylic acid groups in its composition, it represents an excellent template for peptide bond formation. The conjugation of MTX with polymers is a well explored strategy $[4,13,14]$, however, as far as we know, its self-polymerization has never been undertaken. The practical

\footnotetext{
* Corresponding authors.

E-mail addresses: artur@deb.uminho.pt (A. Cavaco-Paulo), carla.silva@ceb.uminho.pt (C. Silva).
} 
application of an oligomeric MTX is envisaged to decrease several adverse side effects associated to its administration like its toxicity and cell resistance [15].

In this work, we explored for the first time the ability of $\alpha$-chymotrypsin to catalyse the oligomerization of methotrexate. The main goal is to produce an oligomeric drug with improved properties in comparison to the monomeric commercial alternative. Molecular dynamics simulations were performed to evaluate the affinity of methotrexate monomer, dimer and trimer, to the protease active site. The resulting oligomers were fully characterized by NMR $\left({ }^{1} \mathrm{H}\right.$ and $\left.{ }^{13} \mathrm{C}\right)$, MALDI-TOF, ESI and DSC.

\section{Experimental}

\subsection{Materials}

All compounds were purchase from Sigma-Aldrich or TCI chemicals, and used without further purifications. $\alpha$-chymotrypsin from bovine pancreas type II, was purchase from Sigma-Aldrich, and used without any further treatment.

\subsection{Methods}

\subsubsection{General procedure for the synthesis of oligomeric methotrexate}

To a solution of MTX di-sodium salt $(10 \mathrm{mg})$ in distillate water $(1 \mathrm{~mL}$ ) was added $\mathrm{NaOH}$ until $\mathrm{pH}=9-10 . \alpha$-chymotrypsin was then added to the reaction $(1 \mathrm{mg})$ suspended in $200 \mu \mathrm{L}$ of water. The solution was placed in a water bath at $50^{\circ} \mathrm{C}, 100 \mathrm{rpm}$ for 7 days. After this time, the enzyme is removed by centrifugation at $2500 \mathrm{~g}$ using vivaspin $10 \mathrm{kDa}$ (Sartorius).

\subsubsection{Activity of $\alpha$-chymotrypsin}

The activity of $\alpha$-chymotrypsin was measured using the universal protease activity assay, with casein as substrate [16]. The activity is calculated by the tyrosine units hydrolysed by the protease, detected at $660 \mathrm{~nm}$ after colorimetric reaction with Folin \& Ciocalteu's phenol reagent. Value of activity obtained: $0.61 \mathrm{U} / \mathrm{mg}$. The values of the activity are given as Units (U) of tyrosine per milligram of protease. The activity of the $\alpha$-chymotrypsin in the medium along time was evaluated by incubating the enzyme under the same reactional conditions for the synthesis of the oligomers, without addition of the methotrexate. At different periods of time, an aliquot of the solution was removed, and the activity was measured as mentioned.

\subsection{3. $N M R$}

${ }^{1} \mathrm{H}$ and ${ }^{13} \mathrm{C}$ NMR spectroscopy were performed using a Bruker Avance III 400 ( $400 \mathrm{MHz}$ for ${ }^{1} \mathrm{H}, 100 \mathrm{MHz}$ for ${ }^{13} \mathrm{C}$ ), using DMSO- $d_{6}$ or $\mathrm{D}_{2} \mathrm{O}$ (Cortecnet, France) as deuteride solvent and the peak solvent used as internal reference. Heteronuclear single quantum coherence spectroscopy (HSQC) and heteronuclear multiple bond correlation (HMBC) were also performed for an accurate signal assignment (Figure S4 and S5). Signal multiplicity is given as: s (singlet), d (doublet), dd (doublet of doublets), $t$ (triplet) and $m$ (multiplet).

NMR characterization of the isolated oligomeric methotrexate: ${ }^{1} \mathrm{H}$ NMR $\left(\mathrm{D}_{2} \mathrm{O}\right): \delta_{\mathrm{H}} 1.98-2.08(\mathrm{~m}, 1 \mathrm{H}), 2.13-2.21(\mathrm{~m}, 1 \mathrm{H}), 2.32(\mathrm{t}$, $J=8.0 \mathrm{~Hz}, 2 \mathrm{H}$ ), 3.21 (s, $3 \mathrm{H}$ ), 4.31 (dd, $J=4.4,8.8 \mathrm{~Hz}, 1 \mathrm{H}$ ), 4.83 (s, $2 \mathrm{H}$ ), 6.92 (d, $J=9.2 \mathrm{~Hz}, 2 \mathrm{H}), 7.75$ (d, $J=8.8 \mathrm{~Hz}, 2 \mathrm{H}$ ) and $8.42(\mathrm{~s}, 1 \mathrm{H})$ ppm.

${ }^{13} \mathrm{C}$ NMR $\left(\mathrm{D}_{2} \mathrm{O}\right): \delta_{\mathrm{C}} 28.5\left(\mathrm{CH}_{2}\right), 34.3\left(\mathrm{CH}_{2}\right), 38.5\left(\mathrm{CH}_{3}\right), 55.4\left(\mathrm{CH}_{2}\right)$, $55.9(\mathrm{CH}), 111.9(\mathrm{CH}), 120.7\left(\mathrm{C}_{\mathrm{q}}\right), 128.4\left(\mathrm{C}_{\mathrm{q}}\right), 129.0(\mathrm{CH}), 146.9(\mathrm{CH})$, $147.7\left(\mathrm{C}_{\mathrm{q}}\right), 151.9\left(\mathrm{C}_{\mathrm{q}}\right), 155.6\left(\mathrm{C}_{\mathrm{q}}\right), 163.7\left(\mathrm{C}_{\mathrm{q}}\right), 169.7(\mathrm{C}=\mathrm{O}), 172.7$ $\left(\mathrm{C}_{\mathrm{q}}\right), 179.3(\mathrm{C}=\mathrm{O})$ and $182.4(\mathrm{C}=\mathrm{O}) \mathrm{ppm}$.

\subsubsection{MALDI-TOF}

MALDI-TOF mass spectra were acquired on a Bruker Autoflex Speed instrument (Bruker Daltonics $\mathrm{GmbH}$ ) equipped with a $1 \mathrm{kHz}$ solid-state smartbeam laser. The samples were prepared as reported [15] using 2,5-dihydroxybenzoic acid (DHB) as matrix, and analysed in the linear negative mode. The number average molecular weight $(\mathrm{Mn})$, weight average molecular weight $(M w)$, polydispersity $(\mathrm{PDI}=M w / M n)$ and average and maximum degree of polymerization ( $\mathrm{DP}_{\text {avg }}$ and $\left.\mathrm{DP}_{\text {max }}\right)$ were calculated using the data obtained from the MALDI spectra [17].

The conversion rate $(p)$ was calculated based on Carothers equation, using the $\mathrm{DP}_{\text {avg }}$ value obtained by MALDI-TOF.

Carothers equation: DPavg $=\frac{1}{1-p}$

\subsubsection{ESI}

Electrospray ionization was performed in a mass detector Thermo Finnigan LxQ (Linear Ion Trap). The analysis was made using a mass detector susceptible of analysis in full scan mode with negative ionization. The mass spectra range was between $\mathrm{m} / \mathrm{z} 50$ and 2000 and a capillary voltage of $29 \mathrm{~V}$ was used. Samples were prepared using ultrapure water (Milli-Q) and methanol (HPLC grade, Fisher Chemical). Prior to analysis, the sample was filtrated using a $0.2 \mu \mathrm{m}$ filter (Whatman).

\subsection{6. $D S C$}

All measurements were conducted on a power-compensated DSC instrument (DSC 6000 Perkin Elmer) with a nitrogen flux of $20 \mathrm{~mL} / \mathrm{min}$, using stainless steel capsules in the temperature range of $20-300^{\circ} \mathrm{C}$ (heating rate: $10{ }^{\circ} \mathrm{C} / \mathrm{min}$, sample weight: $1-2 \mathrm{mg}$ ). The DSC device was calibrated using indium and zinc, both of high purity. The samples were freeze-dried for $24 \mathrm{~h}$ prior to the analyses and each sample was measured at least three times, in order to validate the results.

\subsection{Molecular Dynamics simulations and docking}

Bovine $\alpha$-chymotrypsin, PDB ID: 1OXG, [18] with 2.2 A resolution, comprising residues $1-245$, was chosen for the modelling experiments in this work. The initial procedures used, as Molecular Dynamics simulations, MTXs optimization and analyses, to settle the structures to be used for docking, are described in the Supporting Information. Oneto-one binding model was considered to evaluate individually each MTX molecule to the target $\alpha$-chymotrypsin.

Docking experiments were performed with AutoDock 4.0 [19] and prepared with the AutoDock Tools Software [19]. The middle structure obtained for the native $\alpha$-chymotrypsin, from the MD simulation at $\mathrm{pH}$ 9.5 and $323 \mathrm{~K}$, were used as target macromolecule for the docking experiments. A grid box was set according to the size of the oligomer, ranging from $50 \times 50 \times 50-80 \times 80 \times 100$ in the case of trimer, with a resolution of $0.375 \AA$. The grid box was centered in the active site catalytic triad - and grid potential maps were calculated using AutoGrid 4.0. We chose Lamarckian Genetic Algorithm (LGA) [19,20] as search algorithm. Each docking consisted of 150 independent runs, with a population of 150 individuals, a maximum number of $25 \times 10^{5}$ energy evaluations for MTX monomer and $25 \times 10^{6}$ energy evaluations for dimer and trimer (due the torsions of the oligomers), and a maximum number of 27,000 generations. Additionally, the binding site preference and interactions were identified through the AutoDock tools.

We analysed docking results looking at the binding energy and the Ligand Efficiency (LE), which measures the binding energy per ligand heavy-atom (kcal/HA) to understand how the increase in the oligomer size contributes to the binding. Additional information about molecular modelling studies is presented in the Supporting Information.

\section{Results and discussion}

\section{1. $\alpha$-chymotrypsin-catalysed synthesis of oligomeric MTX}

The use of proteases as polymerization tools for the synthesis of 


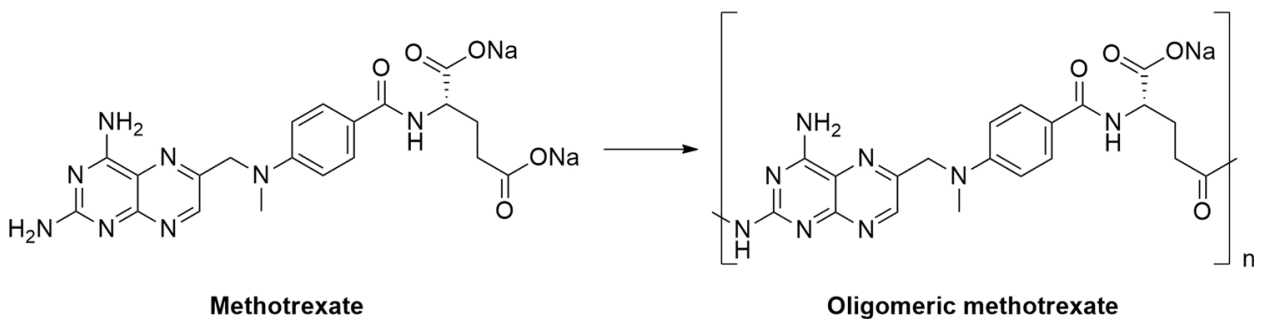

Scheme 1. Reactional scheme for the oligomerization of methotrexate.

peptides is being explored by several researchers $[9,10]$. Considering the chemical structure of methotrexate, composed by two carboxylic acids and two primary aromatic amines, we considered it as a promising template to evaluate the polymerase activity of $\alpha$-chymotrypsin (scheme 1 ). Moreover, the production of a polymeric drug would represent a promising strategy for the pharmaceutical industry regarding its increased interest in the commercialization of these type of drugs [21]. As an amide prodrug, the oligomeric MTX is expected to have higher stability in the human body than the monomeric structure. Moreover, the amide linkages of the oligomeric units, being more prone to hydrolysis by enzymatic action, would improve drug metabolism and decrease dosage administration [22,23]. The improved metabolism is expected to result in a less toxic drug with lower side effects than the commercial monomeric species [22,23].

Methotrexate di-sodium salt was used as starting material to ensure water solubility and provide hydrophilic character to the produced oligomers.

$\alpha$-chymotrypsin was chosen for the MTX oligomerization based on its well-known ability to polymerize peptides [10], showing its high selectivity for the hydrolysis of aromatic amino-acids, such as tyrosine, phenylalanine and tryptophan [24]. The reactional conditions, namely temperature, $\mathrm{pH}$ and time, were optimized to reach the maximum oligomerization degree (Table 1).

Most of the proteases have an optimum working $\mathrm{pH}$ between 7.0-9.0. Based on this feature, on the low basicity of the aromatic amines and on the lack of reactivity of the pteridin ring, the reactions were conducted under basic medium. Similar to what was previously observed by Qin and co-workers [10] for the synthesis of -(KL) $x^{-}$peptides catalysed by $\alpha$-chymotrypsin, we confirmed that no oligomers are produced when the reactions were carried out at neutral $\mathrm{pH}$ (Table 1 , entries 1-3). For an efficient reaction synthesis, it is critical to perform the reactions at alkaline $\mathrm{pH}$, using $\mathrm{NaOH}$ as base $(\approx 9.5$, Table 1 , entries 4-8).

The best reactional outcomes were obtained herein when performing the reactions at $50^{\circ} \mathrm{C}$, which is in accordance with the optimum temperature postulated by other authors for the same protein

Table 1

Reactional conditions tested for the $\alpha$-chymotrypsin-assisted synthesis of methotrexate oligomers.

\begin{tabular}{lllll}
\hline Entry & Temperature & $\mathrm{pH}$ & Time $^{\mathrm{a}}$ & Methotrexate oligomers $^{\mathrm{b}, \mathrm{c}}$ \\
\hline 1 & $\mathrm{RT}$ & 7 & 1 week & 1 \\
2 & $50^{\circ} \mathrm{C}$ & 7 & 1 week & 1 \\
3 & $50^{\circ} \mathrm{C}$ & 7.8 & 1 week & 1 \\
4 & $50^{\circ} \mathrm{C}$ & 9.5 & $48 \mathrm{~h}$ & 3 \\
5 & $50^{\circ} \mathrm{C}$ & 9.5 & $72 \mathrm{~h}$ & 3 \\
6 & $50^{\circ} \mathrm{C}$ & 9.5 & $96 \mathrm{~h}$ & 5 \\
7 & $50^{\circ} \mathrm{C}$ & 9.5 & 1 week & 6 \\
8 & $50^{\circ} \mathrm{C}$ & 9.5 & 2 weeks & 6 \\
9 & $50^{\circ} \mathrm{C}$ & 9.5 & 1 week & $1^{\text {d }}$ \\
\hline
\end{tabular}

\footnotetext{
a Maximum time tested.

b Detected by MALDI-TOF, were 1 unit corresponds to the monomer.

c Maximum oligomeric units detected.

${ }^{\mathrm{d}}$ Control reaction without enzyme.
}

Table 2

Conversion rate (\%), average and maximum degree of polymerization ( $\mathrm{DP}_{\text {avg }}$ and $\mathrm{DP}_{\max }$ ) analysed by MALDI-TOF and electrospray ionization (ESI), for the oligomerization of methotrexate, with and without $\alpha$-chymotrypsin.

\begin{tabular}{lll}
\hline & With $\alpha$-chymotrypsin & Control (without enzyme) \\
\hline Conversion rate $^{\mathrm{a}}$ & $33.4 \%$ & $0 \%$ \\
DP $_{\text {avg }}{ }_{\mathrm{b}}$ & 1.5 & 1 \\
DP $_{\text {max }}$ & 6 & 1 \\
ESI & $975.4 \mathrm{~g} / \mathrm{mol}^{\mathrm{c}}$ & $453.28 \mathrm{~g} / \mathrm{mol}^{\mathrm{d}}$ \\
\hline
\end{tabular}

a Calculated by the Carothers equation.

b Calculated by MALDI-TOF.

c Most abundant specie, corresponding to the dimer. $\mathrm{M}_{\mathrm{w}}$ dimer $=956.8$, where in ESI: $975=956+\mathrm{Na}^{+}-4 \mathrm{H}^{+}$.

${ }^{\mathrm{d}}$ Monomer $\mathrm{M}_{\mathrm{w}}=454 \mathrm{~g} / \mathrm{mol}$ or $498 \mathrm{~g} / \mathrm{mol}$ (di-sodium form), where in ESI: $453=454-1 \mathrm{H}^{+}$.

[25].

During reaction, samples were withdrawn, and continuously monitored by MALDI-TOF, until 2 weeks of reaction (Table 1, entries 4-8). The best reactional outcome was achieved after 1 week of reaction with the formation of oligomers composed by 6 monomeric units $\left(\mathrm{DP}_{\max }\right)$. Longer reactional times led to the recovery of similar-sized MTX oligomers however in lower amount. The DP average calculated (1.5) indicates that the most abundant specie in the reactional medium is the methotrexate dimer, confirmed by MALDI-TOF and ESI (Table 2, Figure S1). After one week of reaction, the enzyme converted $33 \%$ of the monomer molecules into oligomers, while the reaction carried out in the absence of enzyme did not lead to the formation of any oligomeric species (Table 1, entry 9 and Table 2).

In order to ensure an efficient oligomerization, it was imperative to infer the maintenance of the basic $\mathrm{pH}$ during reaction. For this, the $\mathrm{pH}$ was also continuously monitored and after 1 week of reaction, one observed a pH decrease from 9.5 to 8 , and to 7.5, after 2 weeks. We may assume that some of the $\mathrm{NaOH}$ used to basify the medium was consumed during the long reaction, therefore resulting in a $\mathrm{pH}$ decrease. As the reaction occurs the $\mathrm{NaOH}$ is consumed by the low basic amines in the pteridin ring, which were deprotonated, leading to a $\mathrm{pH}$ decrease. The addition of $\mathrm{NaOH}$ was crucial to increase the amines reactivity and proceed with the oligomerization.

It was noteworthy that the activity of $\alpha$-chymotrypsin remained almost unaltered during the first week of reaction (activity of $0.61 \mathrm{U} /$ $\mathrm{mg}$ ), losing only $15 \%$ of the initial activity after 2 weeks (activity of $0.52 \mathrm{U} / \mathrm{mg}$ ). The high stability of the catalyst ensured the efficient catalysis for longer periods of incubation.

\subsection{Synthesis of dimeric MTX - proposed mechanism}

Methotrexate, mainly composed by aromatic rings, is presented herein as a suitable substrate for $\alpha$-chymotrypsin. Based on the data obtained, we have proposed a mechanism for the synthesis of a dimeric unit of methotrexate catalysed by $\alpha$-chymotrypsin (Fig. 1). The reaction is predicted to start by the nucleophilic attack of the $\mathrm{OH}$ terminal group of the serine, in the catalytic triad, to one of the carboxylic groups of MTX (step 1), leading to the formation of the tetrahedral 

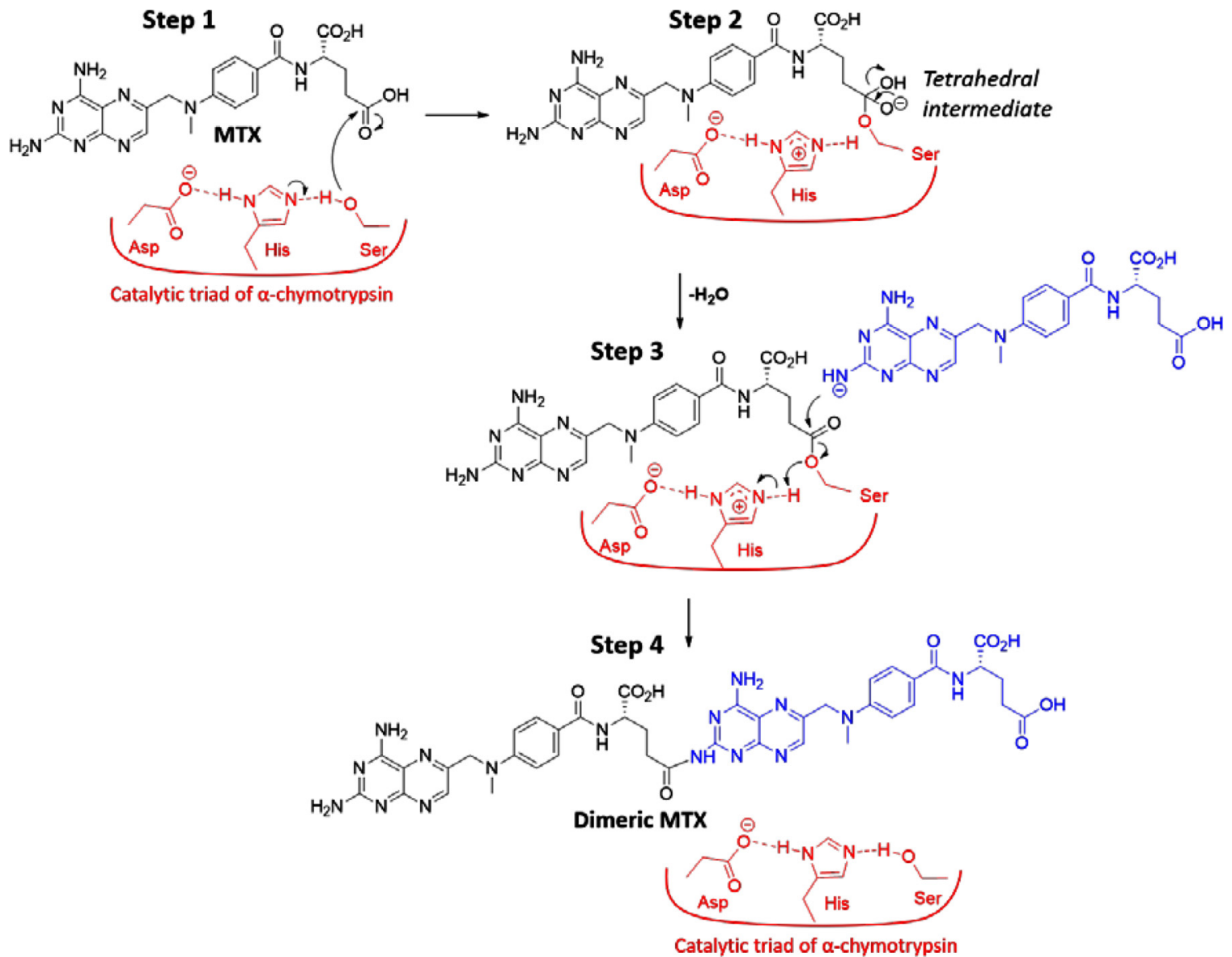

Fig. 1. Proposed mechanism for the synthesis of a dimeric unit of methotrexate catalysed by $\alpha$-chymotrypsin.

intermediate (step 2). The carboxylic group in the glutamic moiety, which suffers the nucleophilic attack as depicted in Fig. 1, is reported as the most reactive [15]. This carboxylic group is also less sterically precluded, which is an important feature to afford oligomerization and an effective catalysis by the protease. After release of a water molecule, an MTX-enzyme complex is formed, through the formation of an ester bond between MTX and the serine residue of the catalytic triad. This reactive bond easily suffers a nucleophilic attack by one of the amines in the pteridin ring of another MTX unit (step 3). The dimeric MTX is then formed and released from the enzyme, where the catalytic triad of $\alpha$-chymotrypsin is restored (step 4).

Considering the data previously described, we may predict that the reaction is not restricted to the synthesis of dimeric units, but it can go further to longer species $\left(\mathrm{DP}_{\max }=6\right)$. The size of the oligomers is however dependent on the affinity of MTX oligomers to the enzyme' active site. Regarding the data obtained, we may infer that $\alpha$-chymotrypsin is able to synthesize species until a maximum of 6 MTX units. However, longer species are hampered to be synthesized due to stereochemical constrains resulting from the molecular weight of MTX ( $498 \mathrm{~g} / \mathrm{mol}$ ), which is comparably higher than the natural substrates of this enzyme (amino acids, peptides).

For a better understanding of these findings, molecular dynamics simulations were performed to evaluate the affinity of MTX and oligomeric MTX to the active site of the enzyme and evaluate the role of the substrate size on the enzyme activity.

\subsection{Molecular dynamics simulations}

Bovine $\alpha$-chymotrypsin (PDB ID: 1OXG) [18] was evaluated under different conditions of temperature and $\mathrm{pH}$ during Molecular Dynamics (MD) simulations. Firstly, the enzyme was evaluated at $310 \mathrm{~K}$ and physiological $\mathrm{pH}$, then at $323 \mathrm{~K}$ and $\mathrm{pH} 9.5$; this second simulation was performed to mimic the experimental conditions used. RMSD results (Figure S2), indicate that the experiment conditions established are the ideal to study the enzyme behaviour, since the enzyme demonstrates to be more stable at the higher temperature and $\mathrm{pH}$. Figure S3 shows the $\alpha$ -chymotrypsin crystallographic structure (A) highlighting the active site, where the catalytic triad composed by HIS 57, ASP 102 and SER 195 takes place, and the electrostatic distribution for this enzyme (B).

MTX and MTX oligomeric structures were predicted at PM6 level [26], a semi-empirical method that performs geometry optimization and charge distribution, making the structures suitable to be used for molecular docking. In the case of MTX, the neutral and negative forms (at $\mathrm{pH}$ 9.5) were evaluated. The structures presented in Fig. 2 were used in Molecular Docking experiments.

Overall, monomer (MTX), dimer and trimer have an increasing flexibility due to the increasing number of torsions. Dimer and trimer (Fig. 2, C-D) optimized with PM6, can undergo more "bent" conformations when submitted to docking, due to the higher number of torsions.

Docking experiments were conducted in order to understand the interactions between MTX and $\alpha$-chymotrypsin, and the role of this enzyme in the synthesis process. We select an area that enwrap the active site with enough space to comprise the MTX units (monomer, dimer or trimer) to dock. Fig. 3 shows the correlation between the MTX and enzyme, and the binding energy involved for each case studied.

MTX complexed to $\alpha$-chymotrypsin, present a binding energy of $-6.94 \mathrm{kcal} / \mathrm{mol}(-29.04 \mathrm{~kJ} / \mathrm{mol})$ and a Ligand Efficiency (LE) of $-0.19 \mathrm{kcal} / \mathrm{HA}(-0.79 \mathrm{~kJ} / \mathrm{HA})$. The monomer has hydrogen bonds with ALA56, GLY59, SER96, TYR94 and THR104, and van der Waals interactions are found with HIS57 and ASP102. For dimeric MTX, GLY59 and TYR94 are also involved in hydrogen bonds, as well as LYS90 and 
<smiles>CN(Cc1cnc2nc(N)nc(N)c2n1)c1ccc(C(=O)N[C@@H](CCC(=O)O)C(=O)O)cc1</smiles><smiles>CN(Cc1cnc2nc(N)nc(N)c2n1)c1ccc(C(=O)N[C@@H](CCC(=O)[O-])C(=O)[O-])cc1</smiles>

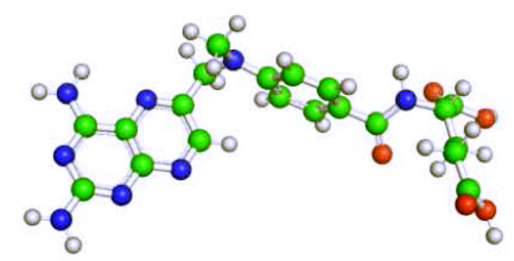

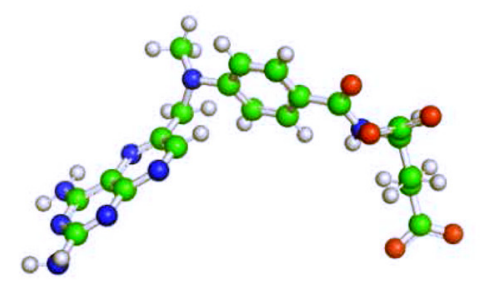<smiles>CN(Cc1cnc2nc(N)nc(N)c2n1)c1ccc(C(=O)N[C@@H](CCC(=O)Nc2nc(N)c3nc(CN(C)c4ccc(C(=O)N[C@@H](CCC(=O)O)C(=O)[O-])cc4)cnc3n2)C(=O)[O-])cc1</smiles>

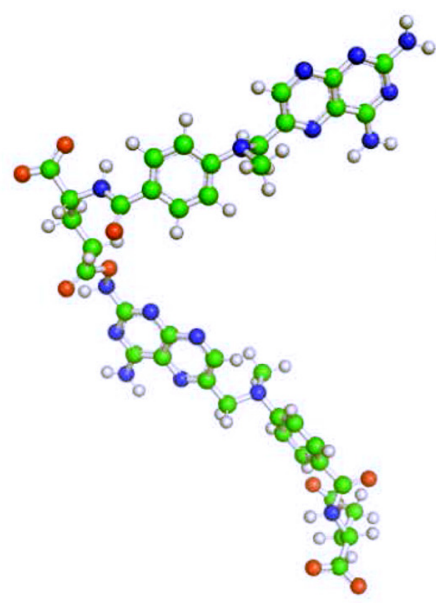

D
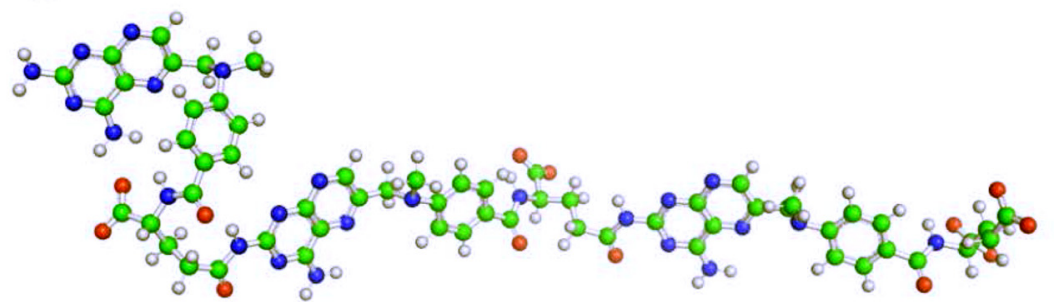

Fig. 2. (A) skeletal and 3-D methotrexate (MTX) structures at $\mathrm{pH} 7.0$ and (B) the deprotonated forms at $\mathrm{pH}$ 9.5. (C) skeletal and 3-D structures of MTX dimer, at $\mathrm{pH}$ 9.5 and (D) shows the trimer 3-D representation. The colour scheme use green for carbon, blue for nitrogen, red for oxygen and white for hydrogen.

ASN95. The binding energy is $-6.35 \mathrm{kcal} / \mathrm{mol}(-26.61 \mathrm{~kJ} / \mathrm{mol})$ in this case, and a LE of $-0.1 \mathrm{kcal} / \mathrm{HA}(-0.42 \mathrm{~kJ} / \mathrm{HA})$. HIS57 is still a close contact for MTX dimer.

The trimer binds to the enzyme with $-5.45 \mathrm{kcal} / \mathrm{mol}(-22.80 \mathrm{~kJ} / \mathrm{mol})$ and LE of $-0.06 \mathrm{kcal} / \mathrm{HA}(-0.25 \mathrm{~kJ} / \mathrm{mol})$. Similarly, HIS57 and ASP102 interact with the trimer. In addition, five hydrogen bonds are found, two with SER96 and the others with LEU97, ASN91, and THR104. In all the three cases, electrostatics interactions are also present, between the carboxylic acids of MTX and the positive region observed in Figure S3 (B).

Farhadian and co-workers recently reported docking experiments with $\alpha$-chymotrypsin $[27,28]$. However, the complexes were not formed in the active site, where the catalytic triad take place. Some other works addressing the docking near the catalytic site do not reveal the complex binding energy for the association of a molecule to the protein [29,30]. Other larger molecules have been described to efficiently bind to $\alpha$-chymotrypsin, however these molecules are used as inhibitors, and therefore cannot be compared to our work [30]. The lack of similar docking approaches makes it difficult to compare our binding preferences and energies with other studies. Moreover, the conversion of the binding energy to association constants is also hard to obtain. In docking experiments, the protein is static, the whole longrange electrostatics is not considered, and no water molecule is present. Therefore, the use of the equation $\Delta \mathrm{G}=-\mathrm{RT} \ln \mathrm{Ka}$, would lead to a rough approximation.

All these interactions demonstrate the ability of MTX to bind to the protease active site, leading to the formation of oligomeric MTX. Even though being possible more interactions of longer MTX forms with the protease, the binding energy decreases discretely as well as the LE per heavy-atom. One may infer that this is due to the energy penalties resulting from the increased number of torsions and desolvation for the bulky forms of MTX (dimer and trimer), since they can undergo to more 


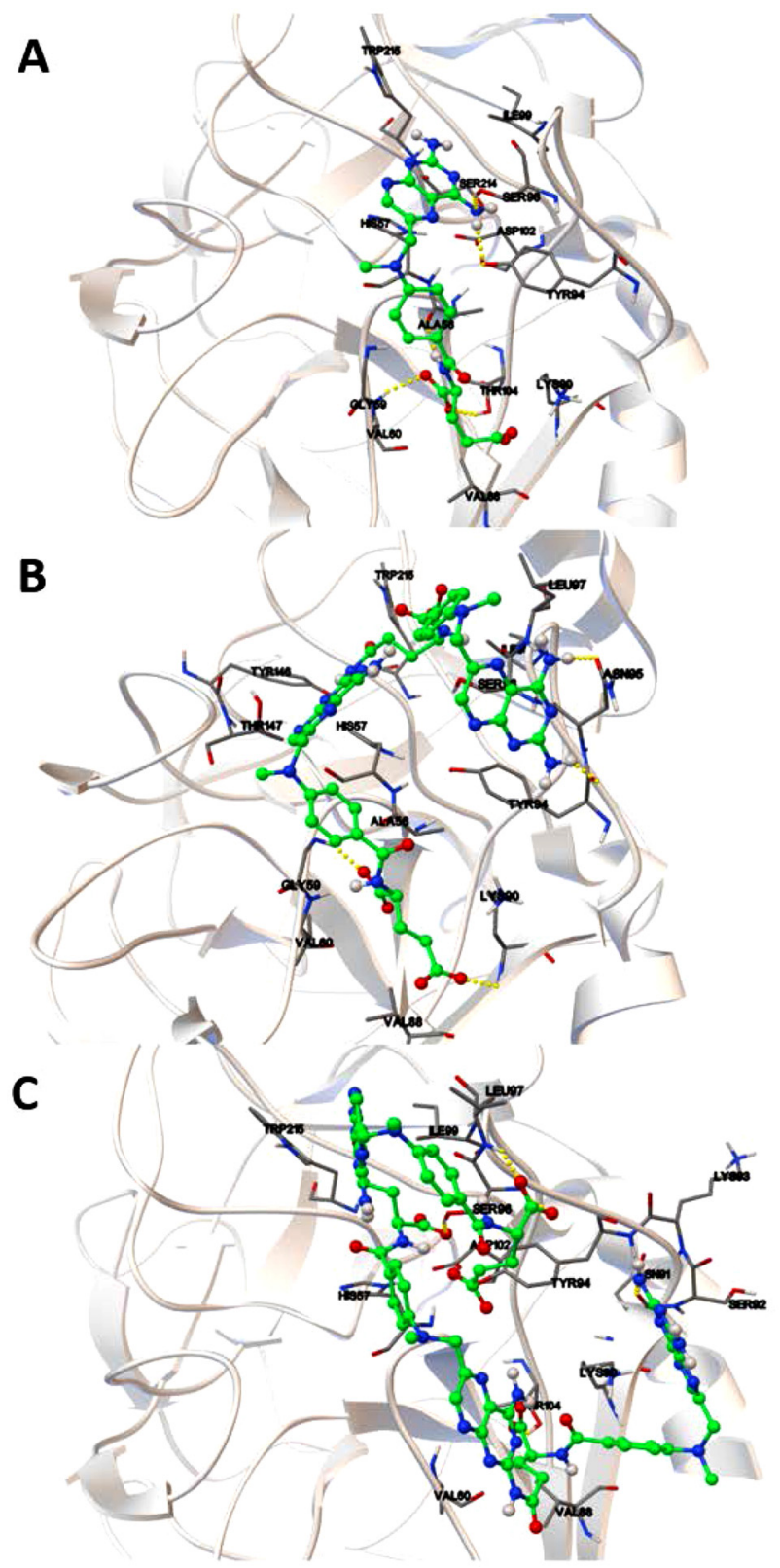

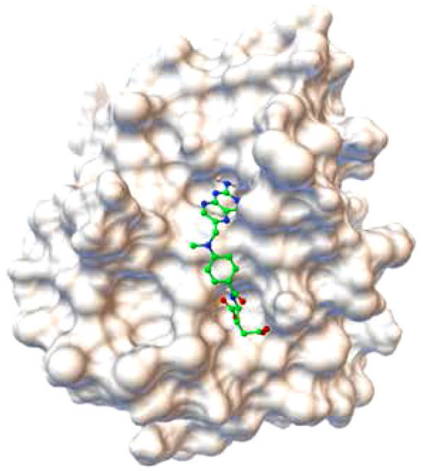

$-6.94 \mathrm{kcal} / \mathrm{mol}$

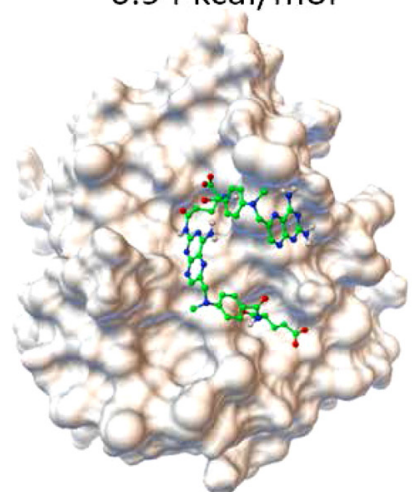

$-6.35 \mathrm{kcal} / \mathrm{mol}$

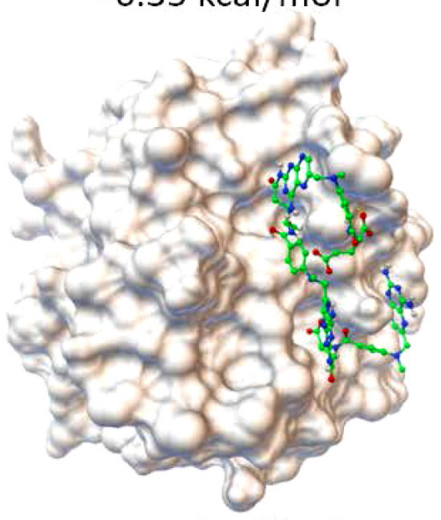

$-5.45 \mathrm{kcal} / \mathrm{mol}$

Fig. 3. Docking poses showing the interaction of $\alpha$-chymotrypsin with the different methotrexate species, and the respective binding energies obtained using AutoDock 4.0: A) $\alpha$-chymotrypsin with methotrexate; B) $\alpha$-chymotrypsin with dimeric methotrexate and C) $\alpha$-chymotrypsin with trimeric methotrexate. Surface/ cavities representation are in the right panel. Enzyme is represented in light grey, hydrogen bonds in yellow dashes and methotrexates following the scheme previous described in Fig. 2. Values in SI units: A) $-29.04 \mathrm{~kJ} / \mathrm{mol}$; B) $-26.61 \mathrm{~kJ} / \mathrm{mol}$ and C) $-22.80 \mathrm{~kJ} / \mathrm{mol}$.

conformations, as previously observed during docking experiments. The results indicate a decrease of the binding energy as the oligomer chain grows, justifying that only a maximum of 6 units of MTX could be biosynthesized by $\alpha$-chymotrypsin.

\subsection{MTX oligomers characterization}

\subsubsection{NMR spectroscopy}

By ${ }^{1} \mathrm{H}$ NMR spectroscopy, it is possible to detect differences between MTX oligomers and the starting material (monomer). In the spectra of free MTX, the signals appeared at $\delta_{\mathrm{H}} 8.56,8.13(\mathrm{NH}), 7.62,7.38(\mathrm{NH})$, $6.81,6.58 \mathrm{ppm}\left(\mathrm{NH}_{2}\right)$, in the aromatic region (Fig. 4A). The spectra of oligomeric MTX (Fig. 4B) show significant chemical shifts in the pteridine ring, $\delta_{\mathrm{H}} 8.15(\mathrm{~b}), 8.14(\mathrm{NH}), 7.62,6.78 \mathrm{ppm}$. The pattern of the signals remained the same as in the monomer MTX, confirming that the amide bond (near proton $\mathrm{g}$ ) is not hydrolysed by the protease during the oligomerization reaction. Bidimensional spectra (HSQC and HMBC) were also performed to allow an accurate signal assignment (Figure S4 and S5).

\subsubsection{MALDI-TOF and ESI}

MALDI-TOF spectra displays the pattern of MTX oligomers catalysed by $\alpha$-chymotrypsin (Fig. 5B) and of the control reaction without enzyme, showing the peak of the monomer below $m / z 500$ (Fig. 5A). By ESI the ion peak corresponding to the monomer is observed at $m / z 453$ (Figure S1 A) and no fragmentation is detected. The most abundant specie detected by ESI on the samples catalysed by $\alpha$-chymotrypsin is a dimer (Figure S1 B).

Regarding the oligomer spectrum (Fig. 5B), (MTX) $)_{1}$ is observed at $475 \mathrm{Da}\left[498-\mathrm{Na}^{+}\right.$], whereas a repetitive pattern of $m / z$ of $\approx 521 \mathrm{Da}$ is detected. This behaviour is observed until a maximum $\mathrm{m} / \mathrm{z}$ of 3112.61 Da, attributed to the longest oligomer obtained composed by 6 


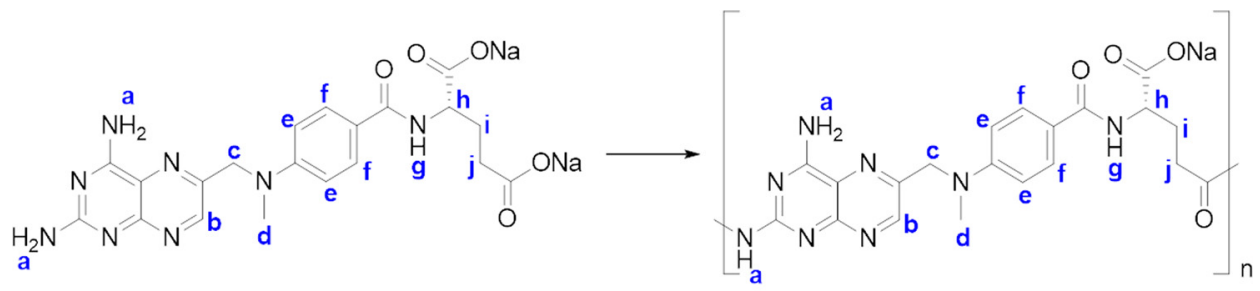

Methotrexate

(A)

Oligomeric methotrexate

(B)

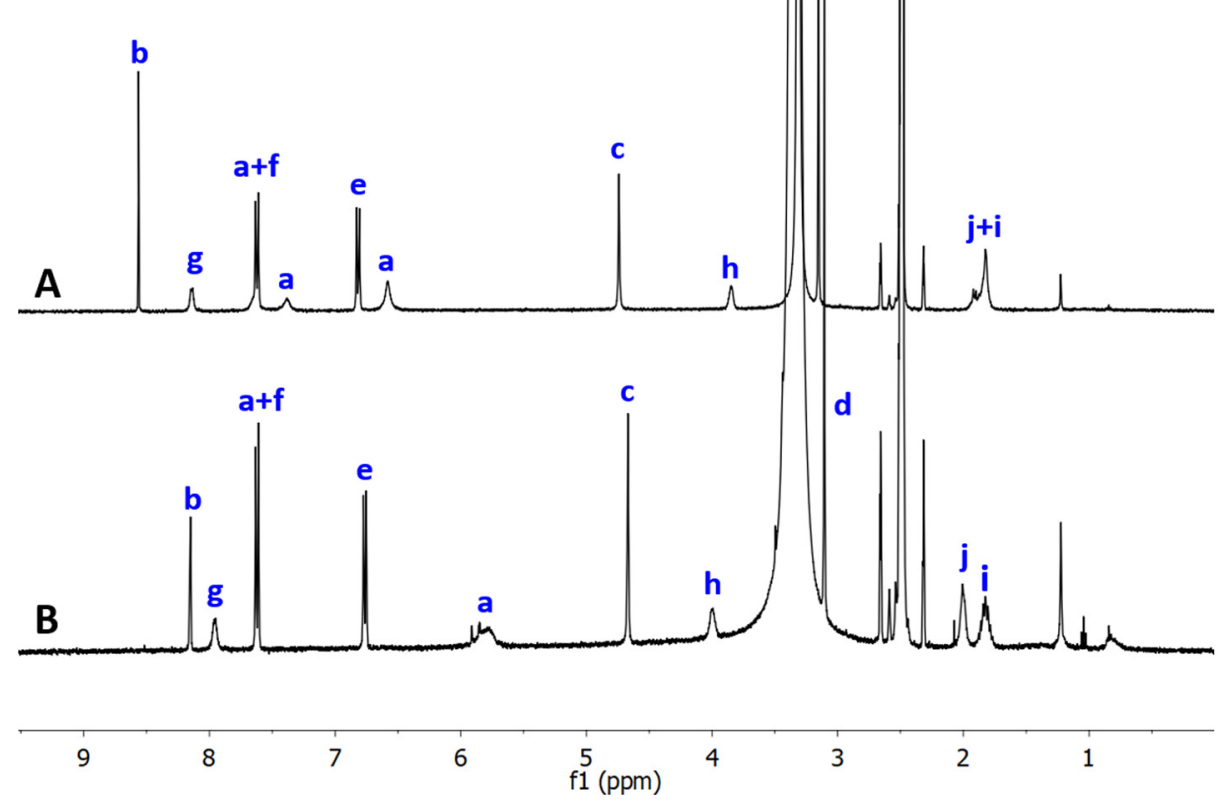

Fig. 4. ${ }^{1} \mathrm{H}$ NMR (DMSO- $d_{6}$ ) spectra of A) methotrexate and B) methotrexate oligomers synthesized by $\alpha$-chymotrypsin.

MTX units. The repeating unit between species $(\approx 521 \mathrm{Da})$ corresponds to the tri-sodium methotrexate, most probably resulting from the presence of the $\mathrm{NaOH}$ on the reactional medium, which may be linked to more than one amine in the pteridin ring. Additional sodium was also found on the recorded ESI spectra of the oligomer.

In Table 3 are summarized the results obtained expressed in terms of number average molecular weight $(M n)$, weight average molecular weight $(M w)$ and PDI $(M w / M n)$. The oligomers produced by the protease showed a $M n$ value of $724.8 \mathrm{~g} / \mathrm{mol}$ and a $M w$ of $1225.7 \mathrm{~g} / \mathrm{mol}$. The polydispersity index obtained was 1.69 , showing some sample heterogeneity.

\subsection{3. $D S C$}

The DSC analysis highlights differentiated thermal behaviour depending on the size of the MTX oligomers (Fig. 6). The monomeric MTX show a melting point at $139^{\circ} \mathrm{C}$ (black line) and no other thermal events are observed at higher temperatures. As the chain length grows higher melting points are expected. The oligomers synthetized by the protease (red line), showed a melting point at $184^{\circ} \mathrm{C}$.

\section{Conclusions}

In this work the synthesis of MTX oligomers assisted by $\alpha$-chymotrypsin was undertaken for the first time. The oligomeric species
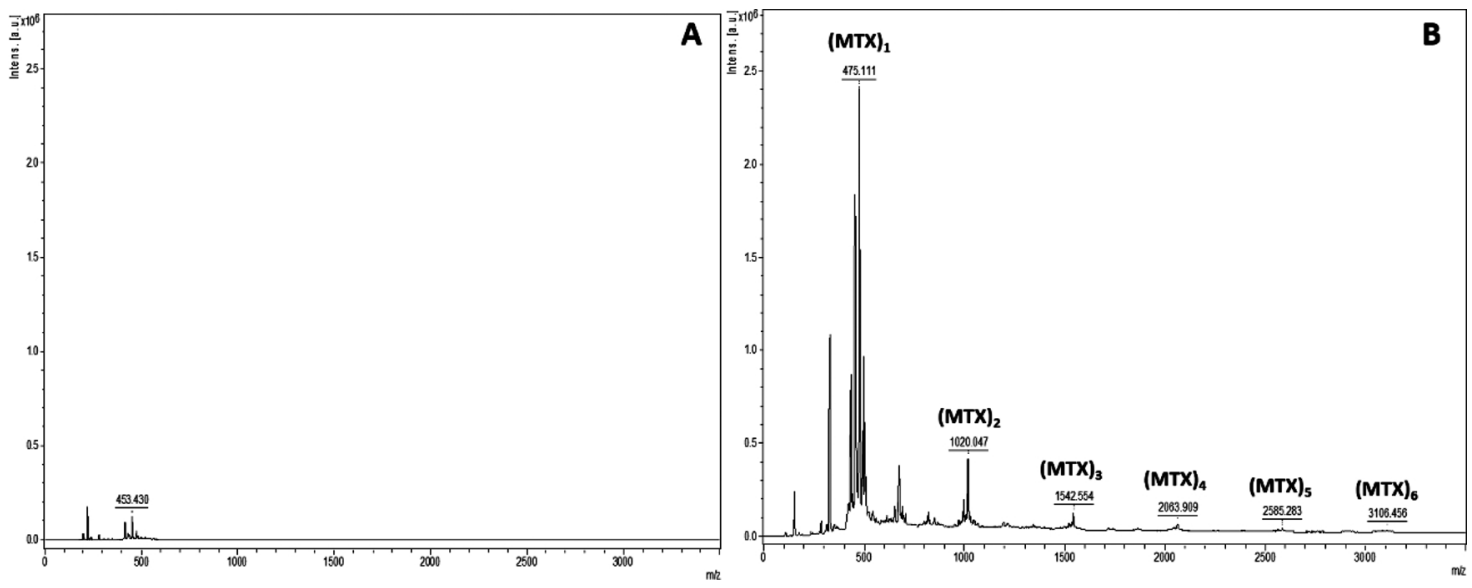

Fig. 5. MALDI-TOF spectra of A) control reaction carried without enzyme, and B) oligomeric methotrexate synthetized by $\alpha$-chymotrypsin. 
Table 3

Number average molecular weight $(M n)$, weight average molecular weight $(M w)$, polydispersity (PDI), average and maximum degree of polymerization $\left(\mathrm{DP}_{\text {avg }}\right.$ and $\left.\mathrm{DP}_{\max }\right)$ of the obtained oligomeric methotrexate catalysed by $\alpha$ chymotrypsin at $50^{\circ} \mathrm{C}$ after 1 week.

\begin{tabular}{ll}
\hline & Oligomeric methotrexate \\
\hline $\mathrm{DP}_{\text {avg }}$ & 1.5 \\
$\mathrm{DP}_{\text {max }}$ & 6 \\
$\mathrm{M}_{\mathrm{n}}$ & 724.8 \\
$\mathrm{M}_{\mathrm{w}}$ & 1225.7 \\
$\mathrm{PDI}$ & 1.69 \\
\hline
\end{tabular}

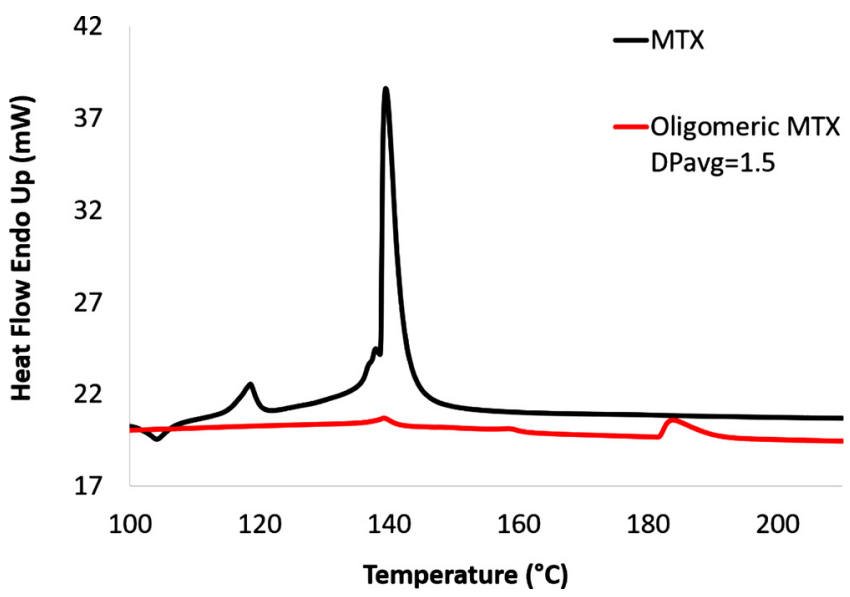

Fig. 6. Differential scanning calorimetry (DSC) curves of methotrexate (MTX) and oligomeric methotrexate; the black line corresponds to the monomer; the red line corresponds to oligomeric MTX synthesized by $\alpha$-chymotrypsin.

obtained were predominantly small (dimers) due to the size of the monomer (MTX, $\mathrm{M}_{\mathrm{w}}=498 \mathrm{~g} / \mathrm{mol}$ ), which imparted stereochemical impediments to the active site. Operational conditions like temperature $\left(50^{\circ} \mathrm{C}\right)$ and $\mathrm{pH}(9-10)$ were found critical for the efficient oligomerization. Molecular dynamics simulations confirmed that as the oligomeric chain grows, its accommodation in the active site is hindered, which is evidenced by a decrease of the binding energy associated $(-6.94 \mathrm{kcal} / \mathrm{mol}$ for the monomer and $-5.45 \mathrm{kcal} / \mathrm{mol}$ for the trimer). The data also revealed that $\alpha$-chymotrypsin is able to synthesize oligomeric species with 6 units, however in a lower extent (33\%).

$\alpha$-chymotrypsin is presented herein as a versatile catalyst for oligomer synthesis, even for substrates that are not naturally catalysed by it, like methotrexate. Moreover, the oligomerization of this drug would represent an alternative route for the treatment of many diseases, by reducing some side effects associated to the monomer administration.

\section{CRediT authorship contribution statement}

Jennifer Noro: Investigation, Methodology, Validation, Writing original draft. Tarsila G. Castro: Investigation, Software, Formal analysis. Artur Cavaco-Paulo: Resources, Supervision, Project administration, Funding acquisition. Carla Silva: Conceptualization, Supervision, Visualization, Writing - review \& editing.

\section{Declaration of Competing Interest}

The authors declare that they have no known competing financial interests or personal relationships that could have appeared to influence the work reported in this paper.

\section{Acknowledgements}

This study was supported by the Portuguese Foundation for Science and Technology (FCT) under the scope of the strategic funding of UIDB/ 04469/2020 unit and BioTecNorte operation (NORTE-01-0145-FEDER000004) funded by European Regional Development Fund under the scope of Norte2020 - Programa Operacional Regional do Norte. The authors thanks to FCT for funding their scholarship: Jennifer Noro (SFRH/BD/121673/2016) and Carla Silva (SFRH/IF/00186/2015).

Tarsila Castro thanks the senior position funded by the European Union through the European Regional Development Fund (ERDF) under the Competitiveness Operational Program (BioCell-NanoART $=$ Novel Bio-inspired Cellular Nano-architectures, POC-A1.1.4-E-2015 nr. 30/ 01.09.2016). Access to computing resources funded by the Project "Search-ON2: Revitalization of HPC infrastructure of UMinho" (NORTE-07-0162-FEDER-000086), co-funded by the North Portugal Regional Operational Programme (ON.2 - O Novo Norte), under the National Strategic Reference Framework (NSRF), through the European Regional Development Fund (ERDF), is also gratefully acknowledged.

\section{Appendix A. Supplementary data}

Supplementary material related to this article can be found, in the online version, at doi:https://doi.org/10.1016/j.procbio.2020.08.004.

\section{References}

[1] J. Li, F. Yu, Y. Chen, D. Oupický, Polymeric drugs: advances in the development of pharmacologically active polymers, J. Control. Release 219 (2015) 369-382.

[2] R. Duncan, The dawning era of polymer therapeutics, Nat. Rev. Drug Discov. 2 (2003) 347-360.

[3] P. Mishra, B. Nayak, R.K. Dey, PEGylation in anti-cancer therapy: an overview, Asian J. Pharm. Sci. 11 (2016) 337-348.

[4] J. Suksiriworapong, V. Taresco, D.P. Ivanov, I.D. Styliari, K. Sakchaisri, V.B. Junyaprasert, M.C. Garnett, Synthesis and properties of a biodegradable polymer-drug conjugate: Methotrexate-poly(glycerol adipate), Colloids Surf. B Biointerfaces 167 (2018) 115-125.

[5] D. Wang, L. Zou, O. Jin, J. Hou, G, Ge, L. Yang, Human carboxylesterases: a comprehensive review, Acta Pharm. Sinic. B 8 (2018) 699-712.

[6] P. Philipps-Wiemann, Chapter 12 - proteases—general aspects, in: C.S. Nunes, V. Kumar (Eds.), Enzymes in Human and Animal Nutrition, Academic Press, 2018 pp. 257-266.

[7] K. Yazawa, K. Numata, Recent advances in chemoenzymatic peptide syntheses, Molecules 19 (2014) 13755-13774.

[8] P.J. Baker, K. Numata, Polymerization of peptide polymers for biomaterial applications, Polym. Sci. (2013) 229-246.

[9] X. Qin, A.C. Khuong, Z. Yu, W. Du, J. Decatur, R.A. Gross, Simplifying alternating peptide synthesis by protease-catalyzed dipeptide oligomerization, Chem. Commun. (Camb.) 49 (2013) 385-387.

[10] X. Qin, W. Xie, S. Tian, J. Cai, H. Yuan, Z. Yu, G.L. Butterfoss, A.C. Khuong, R.A. Gross, Enzyme-triggered hydrogelation via self-assembly of alternating peptides, Chem. Commun. 49 (2013) 4839-4841.

[11] Y. Bedoui, X. Guillot, J. Sélambarom, P. Guiraud, C. Giry, M.C. Jaffar-Bandjee, S. Ralandison, P. Gasque, Methotrexate an old drug with new tricks, Int. J. Mol. Sci. 20 (2019) 5023-5055.

[12] P. Cerqueira, J. Noro, S. Moura, D. Guimarães, C. Silva, A. Cavaco-Paulo, A. Loureiro, PTS micelles for the delivery of hydrophobic methotrexate, Int. J. Pharmaceut. 566 (2019) 282-290.

[13] J. Ren, Z. Fang, L. Yao, F.Z. Dahmani, L. Yin, J. Zhou, J. Yao, A micelle-like structure of poloxamer-methotrexate conjugates as nanocarrier for methotrexate delivery, Int. J. Pharm. 487 (2015) 177-186.

[14] M. Yang, J. Ding, Y. Zhang, F. Chang, J. Wang, Z. Gao, X. Zhuang, X. Chen, Activated macrophage-targeted dextran-methotrexate/folate conjugate prevents deterioration of collagen-induced arthritis in mice, J. Mater. Chem. B 4 (2016) 2102-2113.

[15] J. Noro, R.L. Reis, A. Cavaco-Paulo, C. Silva, Ultrasound-assisted biosynthesis of novel methotrexate-conjugates, Ultrason. Sonochem. 48 (2018) 51-56.

[16] C.Au- Cupp-Enyard, Sigma's non-specific protease activity assay - casein as a substrate, JoVE (2008) e899.

[17] J. Noro, T.G. Castro, F. Gonçalves, A. Ribeiro, A. Cavaco-Paulo, C. Silva, Catalytic activation of esterases by PEGylation for polyester synthesis, ChemCatChem 11 (2019) 2490-2499.

[18] N. Singh, T. Jabeen, S. Sharma, I. Roy, M.N. Gupta, S. Bilgrami, R.K. Somvanshi, S. Dey, M. Perbandt, C. Betzel, A. Srinivasan, T.P. Singh, Detection of native peptides as potent inhibitors of enzymes, FEBS J. 272 (2005) 562-572.

[19] G.M. Morris, R. Huey, W. Lindstrom, M.F. Sanner, R.K. Belew, D.S. Goodsell, A.J. Olson, AutoDock4 and AutoDockTools4: Automated docking with selective 
receptor flexibility, J. Comput. Chem. 30 (2009) 2785-2791.

[20] G.M. Morris, D.S. Goodsell, R.S. Halliday, R. Huey, W.E. Hart, R.K. Belew, A.J. Olson, Automated docking using a Lamarckian genetic algorithm and an empirical binding free energy function, J. Comput. Chem. 19 (1998) 1639-1662.

[21] O. Pillai, R. Panchagnula, Polymers in drug delivery, Curr. Opin. Chem. Biol. 5 (2001) 447-451.

[22] V.R. Guarino, V.J. Stella, Prodrugs of amides, imides and other NH-acidic compounds, in: V.J. Stella, R.T. Borchardt, M.J. Hageman, R. Oliyai, H. Maag, J.W. Tilley (Eds.), Prodrugs: Challenges and Rewards Part 1, Springer, New York, New York, NY, 2007, pp. 833-887.

[23] R. Karaman, Prodrugs design based on inter- and intramolecular chemical processes, Chem. Biol. Drug Des. 82 (2013) 643-668.

[24] J. Feher, 8.5 - digestion and absorption of the macronutrients, in: J. Feher (Ed.), Quantitative Human Physiology, second edition, Academic Press, Boston, 2017, pp 821-833.

[25] M. Custódio, A. Goulart, D. Marques, Rd. Giordano, R. Giordano, R. Monti, Hydrolysis of cheese whey proteins with trypsin, chymotrypsin and carboxypeptidase A, Alim. Nutr. 16 (2005) 105-109.

[26] J.J.P. Stewart, Optimization of parameters for semiempirical methods V: modification of NDDO approximations and application to 70 elements, J. Mol. Model. 13 (2007) 1173-1213.

[27] S. Farhadian, B. Shareghi, L. Momeni, O.K. Abou-Zied, V.A. Sirotkin, M. Tachiya, A.A. Saboury, Insights into the molecular interaction between sucrose and $\alpha$-chymotrypsin, Int. J. Biol. Macromol. 114 (2018) 950-960.

[28] S. Farhadian, B. Shareghi, A.A. Saboury, Exploring the thermal stability and activity of $\alpha$-chymotrypsin in the presence of spermine, J. Biomol. Struct. Dyn. 35 (2017) 435-448.

[29] H. Siddiqui, R. Farooq, B.P. Marasini, R. Malik, N. Syed, S.T. Moin, R. Atta ur, M.I. Choudhary, Synthesis and in vitro $\alpha$-chymotrypsin inhibitory activity of 6chlorobenzimidazole derivatives, Bioorgan. Med. Chem. 24 (2016) 3387-3395.

[30] L. Yang, H. Li, P. Wu, A. Mahal, J. Xue, L. Xu, X. Wei, Dinghupeptins A-D, Chymotrypsin inhibitory cyclodepsipeptides produced by a soil-derived Streptomyces, J. Nat. Prod. 81 (2018) 1928-1936. 